\title{
Marine Protected Areas and the conservation of long-lived marine invertebrates: the Mediterranean red coral
}

\author{
Cristina Linares ${ }^{1,4, *}$, Olivier Bianchimani ${ }^{1}$, Oriol Torrents ${ }^{1}$, Christian Marschal $^{1}$, \\ Pierre Drap $^{2}$, Joaquim Garrabou ${ }^{3}$ \\ ${ }^{1}$ UMR 6540-DIMAR, CNRS-Université de la Méditerranée, Centre d'Océanologie de Marseille, Station Marine d'Endoume, \\ rue Batterie des Lions, 13007 Marseille, France \\ ${ }^{2}$ Laboratoire LSISL UMR 6168, CNRS, 13288 Marseille, France \\ ${ }^{3}$ Institut de Ciencies del Mar, CSIC, Passeig Marítim de la Barceloneta 37-49, 08003 Barcelona, Spain \\ ${ }^{4}$ Present address: Departament d'Ecologia, Universitat de Barcelona, Avda Diagonal 645, 08028 Barcelona, Spain
}

\begin{abstract}
Intensive harvesting has caused important shifts in the size structure of the Mediterranean red coral Corallium rubrum, and continues to hinder the total recovery of exploited populations. Marine Protected Areas (MPAs) offer an excellent opportunity to observe their recovery in the absence of fishing pressures. In this study, we analysed the demographic structure of red coral populations from 3 of the oldest Mediterranean MPAs. The population structures at the beginning of each reserve and after $30 \mathrm{yr}$ of similar management efforts were also forecasted. The 3 MPAs displayed higher size values than those reported for most of the shallow populations and deep-dwelling populations. Differences in the observed size distributions were more closely related to the structure at the beginning of the reserve than to the number of years of protection. The estimated future size distributions showed a significant increase in large colonies; however, the maximum values predicted are far from those measured in pristine populations. Comparisons of harvested and protected populations using different parameters allowed us to identify the percentages of colonies with basal diameter greater than $7 \mathrm{~mm}$ or colony height greater than $100 \mathrm{~mm}$ as the most useful descriptors for evaluating the conservation status of each population. The vulnerability of long-lived marine invertebrates to disturbances is due to their slow population dynamics, hence the importance of active management within MPAs to promote delayed but long-term positive effects on these species. This study provides helpful information for the evaluation of the effectiveness of management measures for coral populations.
\end{abstract}

KEY WORDS: Corallium rubrum · Coral fisheries $\cdot$ Marine Reserves $\cdot$ Size frequency distributions NW Mediterranean Sea

Resale or republication not permitted without written consent of the publisher

\section{INTRODUCTION}

In recent decades, marine communities have been severely threatened by several natural and anthropogenic disturbances (Vitousek et al. 1997, Harvell et al. 1999, Jackson 2001, Harley et al. 2006). For instance, overfishing has severely reduced the abundance of targeted stocks, resulting in truncated age structures by selective fishing of large-sized individuals (Dayton et al. 1995, Jennings \& Kaiser 1998). These disturbances are particularly severe for species with slow growth rates and long life spans (Dayton et al. 1995, Russ \& Alcala 1998).

Several coral species such as Gerardia, Anthipates and Corallium spp. from the Mediterranean Sea and the Pacific Ocean have been extensively harvested for jewellery (Grigg 1989, 1993). These species are longlived with the slowest growing rates of any known past or present fishery (Grigg 1993, Roark et al. 2006) and their conservation is a worldwide concern among ecol- 
ogists and managers (during recent years some attempts have been made to include the genus Corallium in Appendix II of CITES). Increasing our knowledge of long-term population trends under different disturbance scenarios is an essential prerequisite for the conservation and rational management of these organisms.

The Mediterranean red coral Corallium rubrum (Linnaeus, 1758) is a slow-growing, long-lived coral that can reach $50 \mathrm{~cm}$ in height and live for up to $100 \mathrm{yr}$ (Garrabou \& Harmelin 2002, Marschal et al. 2004). Intensive harvesting is the oldest and most significant disturbance for red coral populations, driving significant shifts in the size structure of shallow red coral populations in the Mediterranean Sea (Santangelo et al. 1993a, Tsounis et al. 2007). Although the overall Mediterranean yield has decreased from $\sim 100 \mathrm{t} \mathrm{yr}^{-1}$ before the 1980s to an estimated $\sim 25$ to $30 \mathrm{t} \mathrm{yr}^{-1}$ during recent years (Tsounis et al. 2007), today, red coral fisheries (legal and illegal) continue to hinder the total recovery of exploited populations and most populations can be considered overfished.

Furthermore, recent large-scale mortality events linked to climate change have strongly affected shallow populations, posing new obstacles for the conservation of Corallium rubrum (Garrabou et al. 2001, 2009). The threat of global warming may be particularly significant for species already threatened by other local disturbances (McCarty 2001). The slow growth rates and recruitment limitations displayed by $C$. rubrum underline its vulnerability when faced with these events (Garrabou et al. 2001, Garrabou \& Harmelin 2002) and emphasise the importance of active measures to manage coral fisheries.

During the last decade, several studies have contributed to the understanding of different aspects of the biology of Corallium rubrum, revealing the vulnerability of red coral populations to increasing disturbances (Marschal et al. 2004, Torrents et al. 2005, Tsounis et al. 2007, Torrents 2007 and references therein). Some of these studies have examined the red coral population structures at different sites and depths (Tsounis et al. 2006, Santangelo et al. 2007, Rossi et al. 2008), however, they provide little information regarding the conservation status of populations within Marine Protected Areas (MPAs).

Mediterranean marine reserves offer an excellent opportunity to observe the recovery of shallow red coral populations in the absence of fishing pressures. In general, MPAs have been regarded as efficient tools to maintain and manage fisheries. This protection also allows the enhancement of biodiversity conservation as well as the fulfilment of human needs (Hastings \& Botsford 2003). Nevertheless, it is important to realise that the response to protection depends on the life his- tory of the particular species in question, and in this sense, slow-growing species with infrequent or highly variable recruitment levels will probably respond much more slowly to reserve protection than shortlived, fast-growing species (Halpern \& Warner 2002, Halpern 2003). Furthermore, the success of a target species within a MPA will also depend to some extent on the degree of exploitation and/or status of the species before the creation of the marine reserve, as these factors can potentially influence the speed and degree to which populations respond to protection (Halpern \& Warner 2002). Due to the lack of results about the longterm protection effects on long-lived organisms, data on the effectiveness of older reserves is crucial for the design of future reserves (Parnell et al. 2005).

The oldest Mediterranean marine reserves harbouring red coral are around 20 to 30 yr old (Francour et al. 2001), offering an excellent opportunity to analyse the effects of MPAs on red coral populations. The limited data available indicate an increase in maximum size (Garrabou \& Harmelin 2002) and a shift towards more mature populations at Medes Islands MPA (Tsounis et al. 2006). Despite these positive effects, colony sizes did not reach characteristic values of pristine populations estimated from museum specimens (Garrabou \& Harmelin 2002), most likely as a result of other impacts such as poaching and diving, which do not allow their total recovery (Linares et al. 2003).

As widely recognised, coral harvesting (legal or illegal) principally threatens the largest colonies, so the presence of these colonies may provide information about the exploitation level of red coral populations. Additionally, it has been demonstrated that recreational diving can cause the unintended breakage of colonies of fragile organisms such as red coral (Garrabou et al. 1998, Linares et al. 2003, Coma et al. 2004). The slow growth rate of the red coral Corallium rubrum (Garrabou \& Harmelin 2002, Marschal et al. 2004, Torrents 2007) suggests that full recovery of populations requires decades of effectively non-existent harvesting and other impacts. Therefore, the study of the red coral populations in MPAs is crucial to investigate the potential positive effects of protection, formulate reliable conservation goals and explore the potential duration needed to reach 'pristine' status for red coral populations. In particular, the analysis of size structure in red coral and other colonial invertebrates is frequently used to describe population processes and environmental effects because particular size patterns (changes in the skewness or kurtosis of the size frequency distributions) are expected to result from growth differences with respect to community structure and different disturbance histories (Meesters et al. 2001, McClanahan et al. 2008, Linares et al. 2008). 
In this study, we collected size distribution data from red coral populations in 3 of the oldest Mediterranean MPAs that harbour shallow red coral populations within areas where all kinds of human activities are prohibited except scientific surveys (Francour et al. 2001). Analysis of the size distributions of these red coral populations allowed us to address the following goals. First, to assess the current status of red coral populations not subjected to direct human disturbances (harvesting and frequent diving). Second, to explore the effects of initial population status as well as the expected mid-term effects of protection on red coral populations in the studied MPAs (by estimating past and future size structures). Third, to identify the descriptors that best detect the conservation status of red coral populations using a comparative analysis of available data from the literature of populations submitted to different degrees of protection.

\section{MATERIALS AND METHODS}

Study sites. This study was carried out at 3 of the oldest Mediterranean MPAs: Scandola Nature Reserve, Cèrbere-Banyuls Nature Reserve and Carry-le Rouet Marine Protected Zone (Fig. 1). Scandola Nature Reserve, established in 1975, is located at Corsica Island and was specially created for conservation and scientific purposes. Cerbère-Banyuls Nature Reserve, established in 1974, encompasses 2 zones, a central zone where all activities are prohibited except for scientific pursuits and a peripheral zone where small-scale and recreational fishing and diving are permitted. Carry-le Rouet Marine Protected Zone was created in 1983 and

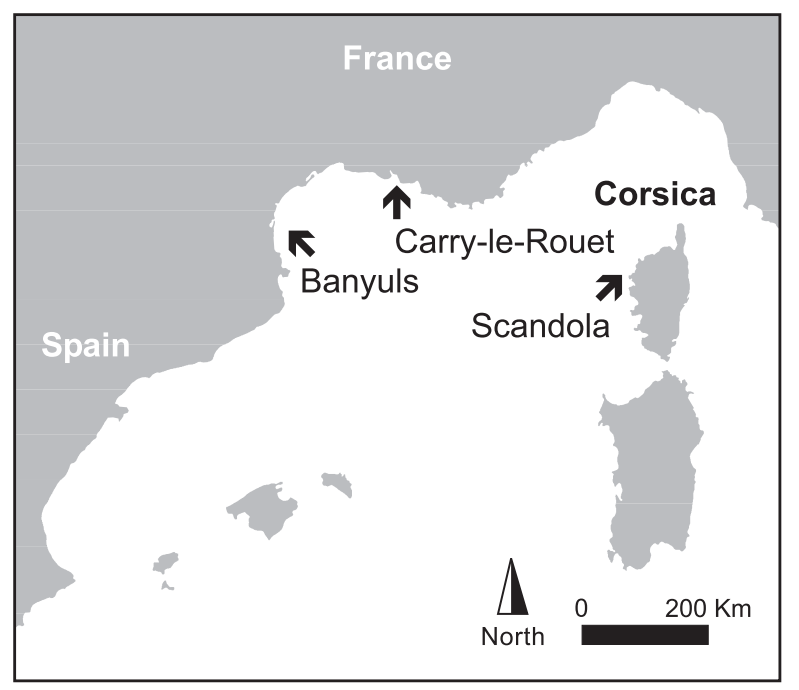

Fig. 1. Location of the 3 French Marine Protected Areas where red coral populations were studied prohibits all activities except snorkelling, boating across the area and scientific surveys (Francour et al. 2001).

These 3 MPAs harbour shallow red coral populations at depths ranging from 19 to $25 \mathrm{~m}$. Three populations located within the same depth range and in total protection zones, where all activities are prohibited, were selected for measurement. This choice avoided potential negative effects of frequent diving (Garrabou et al. 1998, Linares et al. 2003, Coma et al. 2004) on the recovery of populations and, thus, guaranteed that the disturbance regimes affecting these selected populations were equivalent.

Red coral population structure in $30 \mathrm{yr}$ old MPAs. At each location, several permanent plots were set up using PVC screws fixed to holes in the rocky substratum. The plots were randomly selected within welldeveloped red coral populations. Each plot was variable in length, depending on the complexity of the substratum, and $40 \mathrm{~cm}$ wide. The total area covered in each site was about $2 \mathrm{~m}^{2}$. Due to the fragility of the red coral colony, photographic sampling was used to study the current structure and population dynamics of this species. Transects were photographed using a NIKON D70 with a housing and 2 electronic strobes. In each sampling, a cord was deployed between the screws and $20 \times 20 \mathrm{~cm}$ quadrats assembled with a scale were sequentially positioned and photographed above and below the cord throughout the length of each transect. Two photographs from each quadrat (using 2 slightly different angles, $\sim 30^{\circ}$ ) were used for analysis with photogrammetric techniques (Drap 1997). This technique allows measurements to be obtained in 3 spatial dimensions, thus considerably increasing the quantity and precision of the measures. From each photograph, we estimated the basal diameter, the maximum height and the number of branches of each colony, as well as the density of colonies within each quadrat. Sampling was carried out in November 2003 for the Scandola population and in June 2005 for the Banyuls and Carry-le-Rouet populations.

Evaluation of protection effects of $30 \mathrm{yr}$ old MPA red coral populations. The size distributions at the declaration dates of the MPAs were reconstructed in order to evaluate how effectively MPAs achieve the expected shift towards increasing abundance of largesized colonies. For this reconstruction, growth rates estimated from different populations through a new ageing method developed for red coral (Marschal et al. 2004, Torrents 2007) were used. This reconstruction allowed us to analyse the population structure at the beginning of the declaration of each studied MPA, overcoming the general lack of historical demographic data. On the other hand, projections of population size structure $30 \mathrm{yr}$ after the date of size structure sampling 
were also performed to evaluate future effects of protection. These past and future estimations were performed from the size structure obtained at each study site and assuming a constant annual mortality rate of about $1 \%$ for all colony sizes, which is based on the long-term monitoring of a red coral population (Garrabou \& Harmelin 2002) and uses the growth rates estimated at each location (Torrents 2007).

Growth rates were obtained from the analysis of annual growth rings revealed after staining the organic matrix in thin slabs obtained from basal colony sections. Prior to the observation of growth rings, the slabs were decalcified in $2 \%$ acetic solution for 4 to $5 \mathrm{~h}$. After rinsing, the slabs were stained with Toluidine blue at $5 \%$ for 10 to $30 \mathrm{~s}$ before growth ring analysis. In situ labelling experiments of red coral colonies with calceine demonstrated the annual periodicity of growth rings observed with this new method (see Marschal et al. 2004 for further details). For the quantification of growth rates, 5 photographs enlarging 5 different areas from the colony section plus 1 photograph with an overall view were obtained. The photographs were taken with a stereomicroscope $\left(\right.$ Leica $^{\odot}$ MZ16) connected to both a computer and a video camera (Evolution $^{\text {TM }}$ LC Color - PLA662). All annual growth rates were obtained from stereomicroscope images analysed with Visilog ${ }^{\circledR} 6.0$ - TNPC ${ }^{\circledR} 4.1$ using appropriate calibrated images.

For each colony, annual growth rates were quantified by measuring the length of annual growth rings from the last 10 yr before sampling in 5 areas, i.e. 50 growth rates were obtained per colony. The average growth rate in each population was calculated from growth rates measured in 10 colonies. Therefore, for each population, growth rates were based on 500 annual growth rate measurements. In order to use annual diameter growth rate for the reconstruction and projection of size structures, the radial linear measures obtained from the analysis of photographs were multiplied by 2 . Thus growth rate data provided in this study correspond to annual diameter growth rate $\left(\mathrm{mm} \mathrm{yr}^{-1}\right)$.

Colonies collected for growth rate measurements were sampled in 2003 in Carry-le-Rouet and in 2004 in Scandola. Growth rates obtained at Scandola and Carry-le-Rouet MPAs ranged between 0.132 and
$0.135 \mathrm{~mm} \mathrm{yr}^{-1}$ (Torrents 2007). No data on growth rates were available for the Banyuls population. For this population, we instead used the mean growth rate $\left(0.15 \mathrm{~mm} \mathrm{yr}^{-1}\right)$ obtained from the study of 12 red coral populations analysed along French NW Mediterranean coasts (see Torrents 2007 for further information). Bearing in mind that Torrents (2007) showed a low variability in growth rates among populations, we contend that the lack of an annual growth rate for the Banyuls population does not introduce any meaningful bias into our estimates.

Assessing the conservation status of red coral populations. To evaluate the effects of protection from harvesting and frequentation, we compared our data with results obtained from the literature for populations submitted to harvesting and/or frequentation (demographic data from 11 red coral populations located in Italy, France and Spain - only 1 [Medes Islands] found in a marine reserve-were compiled; see Table 2). The descriptors used for this comparison were (1) the mean and maximum values of basal diameter and maximum height, (2) the mean diameter and height obtained from the 30 largest colonies, since these have been noted as useful indicators in a previous study (Garrabou \& Harmelin 2002), and (3) the percentage of colonies with basal diameter greater than $7 \mathrm{~mm}$ (the minimum legal size of harvesting according to current Spanish regulations, note that no restrictions regarding the size of harvested colonies exist in France) and the percentage of colonies with height higher than $100 \mathrm{~mm}$. Pearson's product-moment correlation (Sokal \& Rohlf 1995) was used to examine the relationships between different descriptors.

\section{RESULTS}

\section{Red coral populations in 30 yr old MPAs}

Colony density was highly variable among the 3 studied populations (ranging between 5.5 and 1.9 colonies per $400 \mathrm{~cm}^{2}$, Table 1). Similarly, the mean number of branches also showed significant differences among populations (between 6 and 13 branches per colony; Kruskal-Wallis test, $\mathrm{p}<0.01$ ), but in con-

Table 1. Corallium rubrum. Characteristics of studied populations: depth, number of colonies (N), density (number of colonies per $400 \mathrm{~cm}^{2}$ quadrats; number of colonies per $\mathrm{m}^{2}$ ), basal diameter $(\mathrm{mm})$, maximum height $(\mathrm{mm})$ and number of branches

\begin{tabular}{|c|c|c|c|c|c|c|c|c|c|c|c|c|c|c|}
\hline \multirow[t]{2}{*}{ Site } & \multirow[t]{2}{*}{ Depth } & \multirow[t]{2}{*}{$\mathrm{N}$} & \multicolumn{2}{|c|}{$\mathrm{N}$ per quadrat } & \multirow{2}{*}{$\begin{array}{l}\mathrm{N} \mathrm{m}^{-2} \\
\text { Mean }\end{array}$} & \multicolumn{3}{|c|}{ Basal diameter } & \multicolumn{3}{|c|}{ Height } & \multicolumn{3}{|c|}{ No. of branches } \\
\hline & & & Mean & $\mathrm{SD}$ & & Mean & $\mathrm{SD}$ & Max & Mean & $\mathrm{SD}$ & $\operatorname{Max}$ & Mean & $\mathrm{SD}$ & Max \\
\hline Banyuls & $23-25$ & 109 & 5.5 & 2.7 & 137 & 5.9 & 3.1 & 16.9 & 66.7 & 37.6 & 166.3 & 6.7 & 6.4 & 41 \\
\hline Carry & $24-25$ & 89 & 1.9 & 2.8 & 47 & 6.2 & 4.8 & 19.1 & 74.3 & 46.5 & 152.6 & 13.5 & 12.1 & 42 \\
\hline Scandola & $19-22$ & 166 & 2.8 & 2.5 & 70 & 8.9 & 5.8 & 29.7 & 67.2 & 41.5 & 168.5 & 8.3 & 7.8 & 45 \\
\hline
\end{tabular}


trast the maximum values recorded (around 40 to 45 branches) were similar at the 3 locations (Table 1).

The mean diameter obtained in the Scandola MPA $(8.9 \mathrm{~mm})$ was higher than the values recorded for the Banyuls and Carry-le-Rouet MPAs (5.9 and $6.2 \mathrm{~mm}$, respectively). The Scandola population also displayed marked differences with respect to the maximum colony size (29.7 mm basal diameter). Significant differences were found among the 3 studied populations (Kruskal-Wallis test, p < 0.001) (Table 1). Regarding colony height, the 3 studied populations showed similar values for mean colony height (between 66.7 and $74.3 \mathrm{~mm}$ ) and maximum colony height (between 152.6 and $168.5 \mathrm{~mm}$ ) (Table 1). No significant differences were found for colony height (Kruskal-Wallis test, $\mathrm{p}=$ 0.480).

The basal diameter frequency distributions of the 3 studied populations are shown in Fig. 2a. The Banyuls and Scandola populations showed more or less bellshaped structures, unlike that obtained for Carry-leRouet which displayed the highest proportion of very small colonies $(18 \%$ of colonies with basal diameter

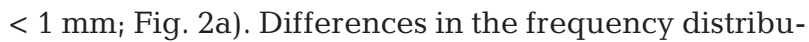
tion of colony height were also observed among the 3 locations (Fig. 2b). The Banyuls and Scandola populations showed similar distributions, while the Carryle-Rouet height frequency distribution was markedly different, displaying a bimodal distribution (Fig. 2b).

\section{Evaluation of protection effects on red coral populations in $30 \mathrm{yr}$ old MPAs}

The differences between the present and past size frequency distributions estimated for the beginning of each MPA was highlighted in the case of the Banyuls MPA (Fig. 3). At the creation of this MPA (1974), the red coral population showed a size distribution remarkably skewed to the right, with the lowest proportion of colonies with basal diameters greater than $7 \mathrm{~mm}$ (6 vs. $30 \%$ in the past and current distributions, respectively). In contrast, the past and current size distributions in the Carry-le-Rouet and Scandola MPAs did not show strikingly differences, especially regarding the proportion of colonies with basal diameters larger than $7 \mathrm{~mm}$ (33 vs. $42 \%$ in Carry-le-Rouet MPA and 36 vs. $54 \%$ in Scandola MPA) (Fig. 3).

A comparison of the present and the estimated future size distributions showed a significant change regarding the proportion of the largest colonies in each population (Fig. 3). According to this estimation, there was a $\sim 5$-fold increase in the proportion of colonies with basal diameters larger than $15 \mathrm{~mm}$ in Banyuls (from 1 to $5 \%$ of the colonies) and Carry-le-Rouet (from 5 to $21 \%$ ), whereas the estimated increase in Scandola was 2-fold (from 14 to $25 \%$ ). The maximum basal diameters expected for each of the study locations were 20.8, 23.1 and $33.6 \mathrm{~mm}$ for Banyuls, Carry-le-Rouet and Scandola populations, respectively.

\section{Assessing the conservation status of red coral populations}

At the 3 study locations, mean values for both size descriptors (mean basal diameter and mean maximum height) were higher than those described for the harvested populations (Table 2). The Italian and 2 French harvested populations showed the lowest values for basal diameter and colony height, except for the mean colony height $(69.3 \mathrm{~mm})$ found for the Italian population. Surprisingly, however, the maximum values for basal diameter $(32 \mathrm{~mm})$ and colony height $(200 \mathrm{~mm})$ were measured in harvested populations located along the NE Spanish littoral (Table 2).

When analysing the mean basal diameter and colony height for the 30 largest colonies at each location, differences between harvested and non-harvested populations were found depending on the descriptor used. Regarding the basal diameter, the Scandola population showed a strikingly high mean diameter $(18.6 \mathrm{~mm})$ in comparison to all other populations (Table 2). However, the mean basal diameter for the largest colonies in the Banyuls and Carry-le-Rouet populations were similar to those found in harvested and non-harvested (Medes Islands) sites along the NW Spanish coast (ranging between 9.8 and $13.7 \mathrm{~mm}$, Table 2). With respect to the mean colony height of the largest colonies, the values found for the 3 MPAs as well as for Medes Islands (ranging between 111.3 and $130.5 \mathrm{~mm}$ ) were higher than the values reported for harvested populations (from 38.5 to $98.3 \mathrm{~mm}$, Table 2).

The proportion of the colonies with basal diameters greater than $7 \mathrm{~mm}$ showed a clear-cut pattern between harvested and non-harvested populations. The 3 studied MPA populations and the Medes Islands population displayed values (between 30 and 54\%) much higher than those obtained for harvested populations (between 0.2 and $13.1 \%$; Table 2). Moreover, the proportion of colonies with a height higher than $100 \mathrm{~mm}$ estimated in the 3 studied populations (between 18 and $31 \%$ ) was strikingly higher than both the harvested populations and the Medes Islands population (lower than $1.5 \%$ of the colonies, Table 2 ).

The mean basal diameter showed a significant correlation with the percentage of colonies with basal diameters larger than $7 \mathrm{~mm}(\mathrm{r}=0.918, \mathrm{p}<0.001)$ as well as with the mean basal diameter obtained from the 30 largest colonies of each population $(r=0.879, \mathrm{p}<$ 0.001) (Fig. 4a,b), showing a clear distinction between 

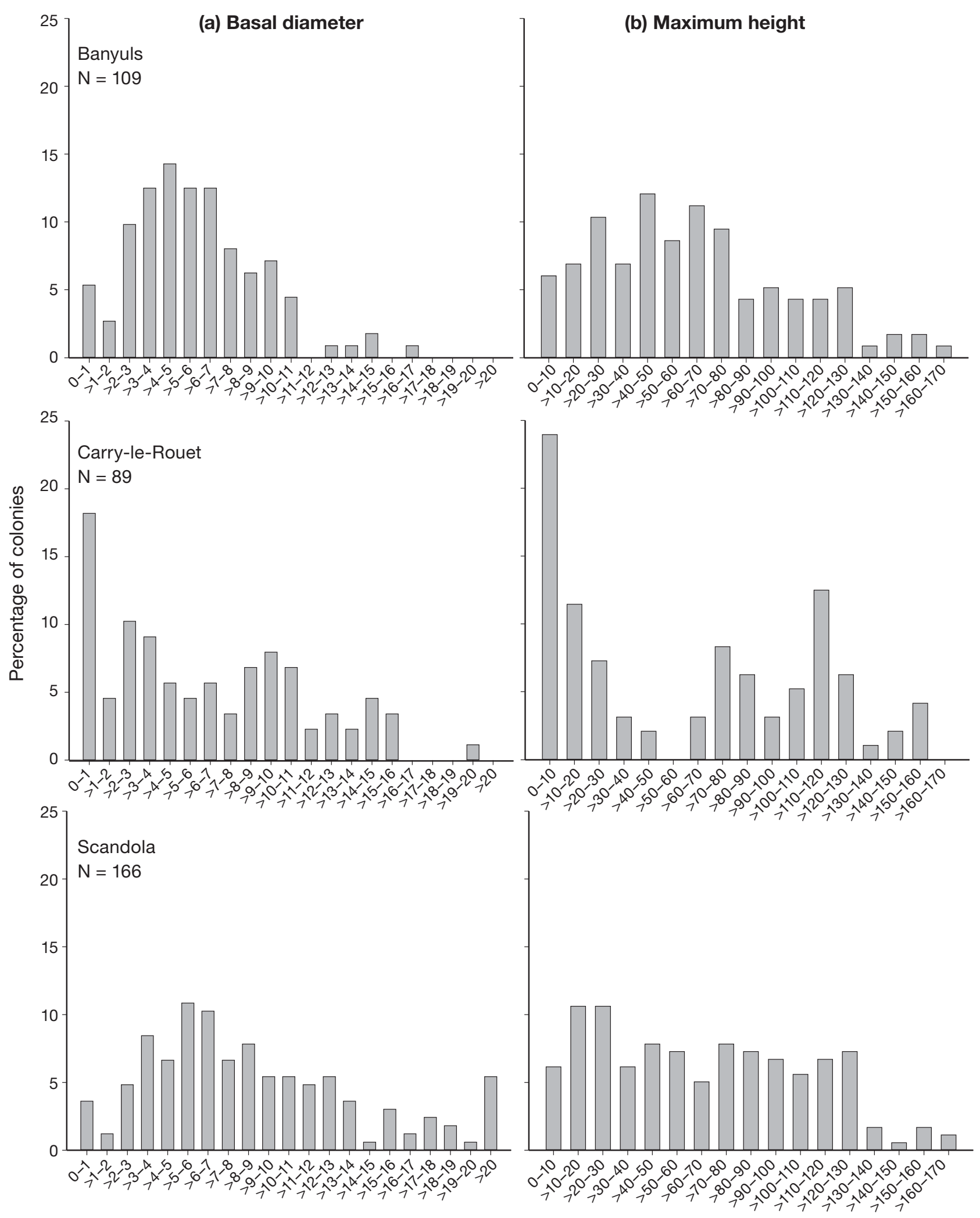

Basal diameter (mm)

Maximum height $(\mathrm{mm})$

Fig. 2. Corallium rubrum. Size frequency distributions of the 3 studied populations. (a) Basal diameter. (b) Maximum height. $\mathrm{N}=$ number of colonies measured in each study location 


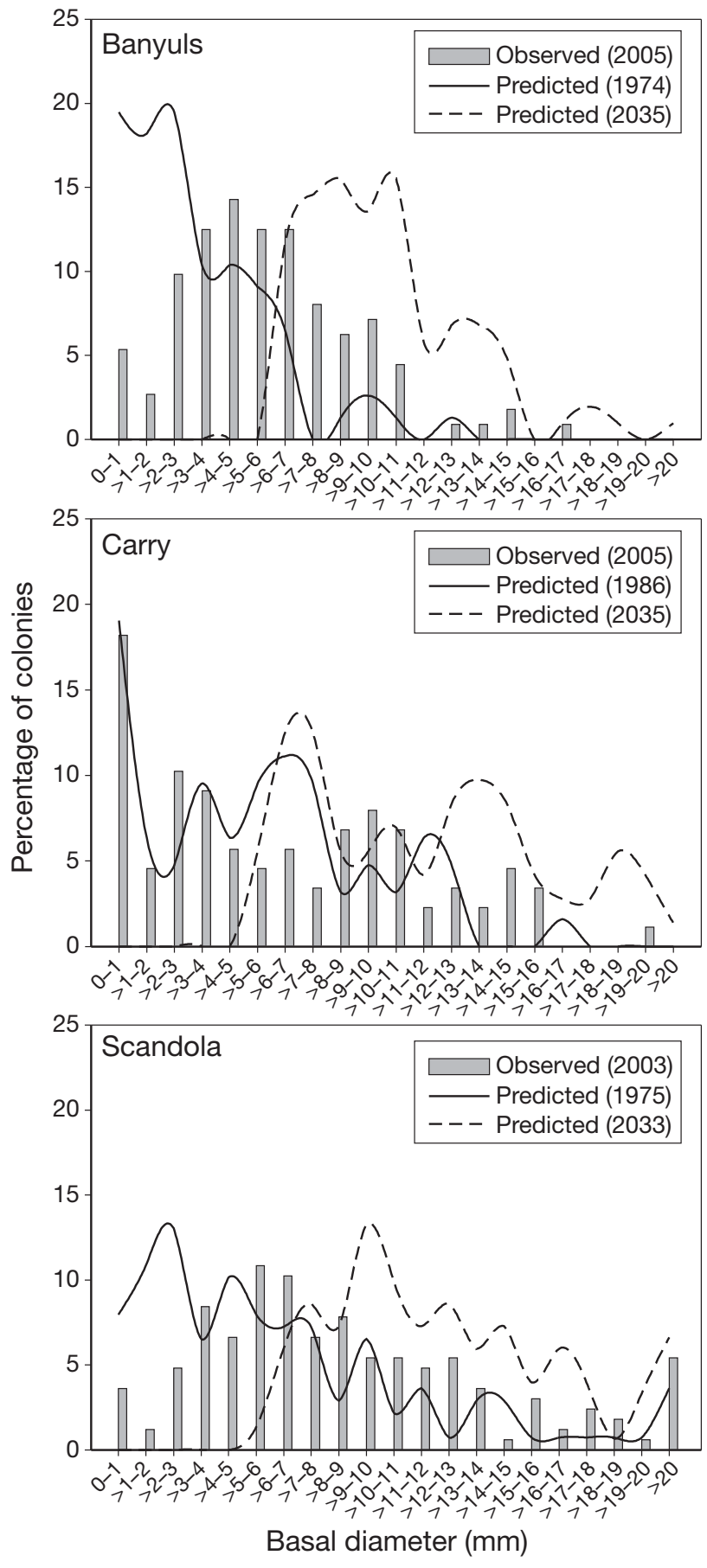

Fig. 3. Corallium rubrum. Current and predicted past and future size frequency distributions based on estimated growth rates

harvested and non-harvested populations. Similarly, mean colony height showed a significant relationship with both the percentage of colonies with height greater than $100 \mathrm{~mm}(\mathrm{r}=0.945, \mathrm{p}<0.001)$ and the mean colony height obtained from the 30 largest colonies ( $\mathrm{r}=0.849$, $\mathrm{p}<0.001$ ) (Fig. 4c,d). In this case, both relationships showed a clear separation between the 3 studied MPAs and the rest of the coral populations, including the Medes Islands MPA (Fig. 4c,d).

\section{DISCUSSION}

This study provides valuable demographic data to help infer the long-term effects of effective protection on red coral populations at 3 of the oldest Mediterranean MPAs (Francour et al. 2001), which encompass an important geographic scale (up to about $450 \mathrm{~km}$ ). The 3 studied MPAs harbour well-developed red coral populations at shallow depths, showing remarkable values for mean basal diameter and colony height as compared to the values reported for most of the shallow red coral populations studied to date (Garrabou et al. 2001, Bianchimani 2005, Tsounis et al. 2006, Santangelo et al. 2007). Similarly, the size frequency distributions observed at the 3 MPAs showed a high proportion of colonies in the largest diameter and height classes, especially in the Scandola MPA, in contrast to the size distributions reported in previous studies (Garrabou \& Harmelin 2002, Bianchimani 2005, Tsounis et al. 2006, Santangelo et al. 2007). On the other hand, the density values obtained for the 3 studied populations (ranging between 47 and 137 colonies $\mathrm{m}^{-2}$ ) were similar to those reported for shallow red coral populations along the NW Spanish coastline (mean density about 127 colonies $\mathrm{m}^{-2}$, Tsounis et al. 2006) but strikingly lower than the values reported for populations at a similar depth range in the Ligurian Sea (ranging between 300 and 5247 colonies $\mathrm{m}^{-2}$, Santangelo et al. 1993b, Bramanti 2003, Bavestrello et al. 2009). These differences can be explained by the high recruitment rates observed for the Italian red coral populations (Bramanti et al. 2007), which differ greatly from those reported for several Spanish and French populations (Garrabou et al. 2001, Garrabou \& Harmelin 2002, Linares et al. 2003). Therefore, population dynamics differed across geographic areas, diverging from the expected trade-off between recruitment and lifespan reported for terrestrial and marine long-lived organisms (Forbis \& Doak 2004, Franco \& Silvertown 2004, Linares et al. 2007)

The sizes of red coral colonies observed in the 3 studied MPAs point out that the protection measures established between 22 and $31 \mathrm{yr}$ ago have allowed for the conservation of populations with exceptionally large colonies in shallow waters, which are currently quite scarce along the NW Mediterranean coast. Although it is obvious that shallow populations are exposed to greater harvesting intensity, recent remotely operated vehicle (ROV) surveys of deep red coral populations at Cap de Creus (Spain) and the Calabrian coast (Italy) showed that the mean diameter, maximum height and 
Table 2. Corallium rubrum. Comparison of different size descriptors obtained from the 3 studied populations and 9 shallow red coral populations obtained from the literature. $\mathrm{D}$ = basal colony diameter, $\mathrm{H}=$ maximum colony height

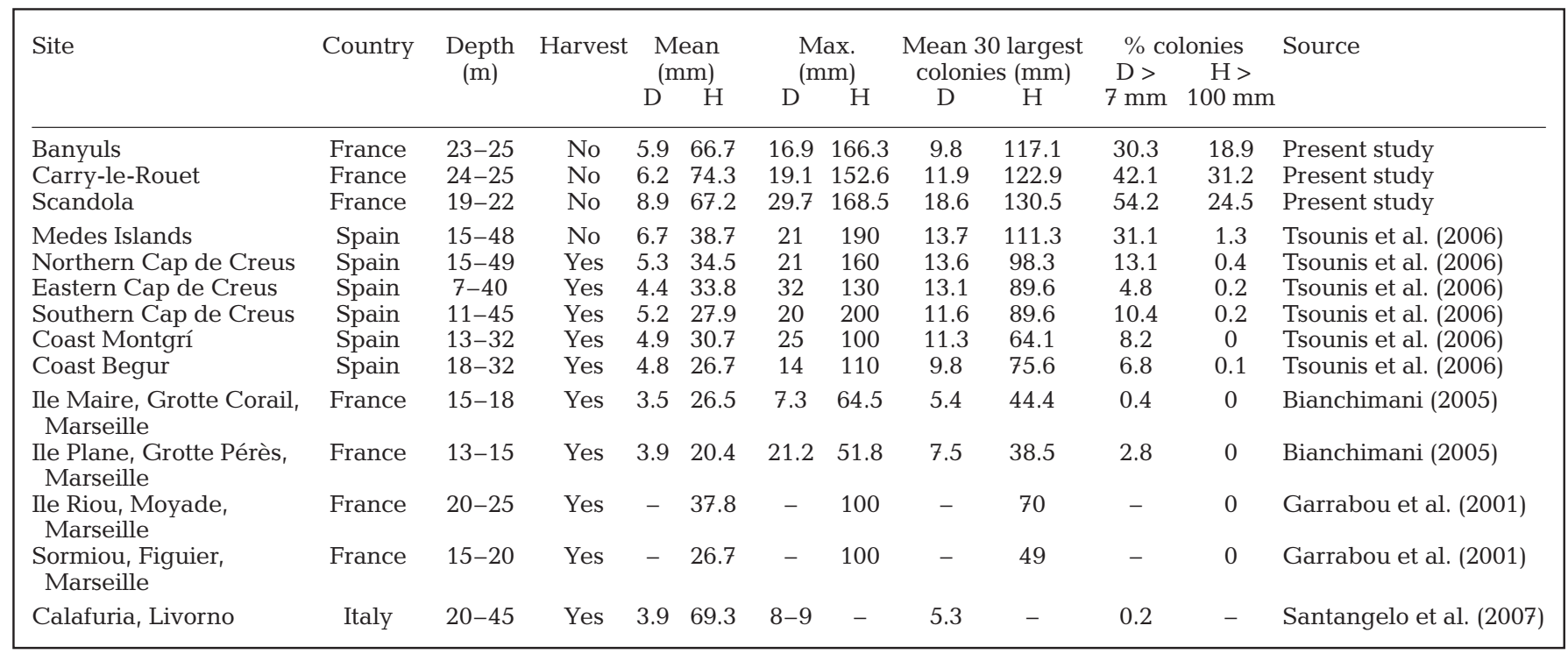
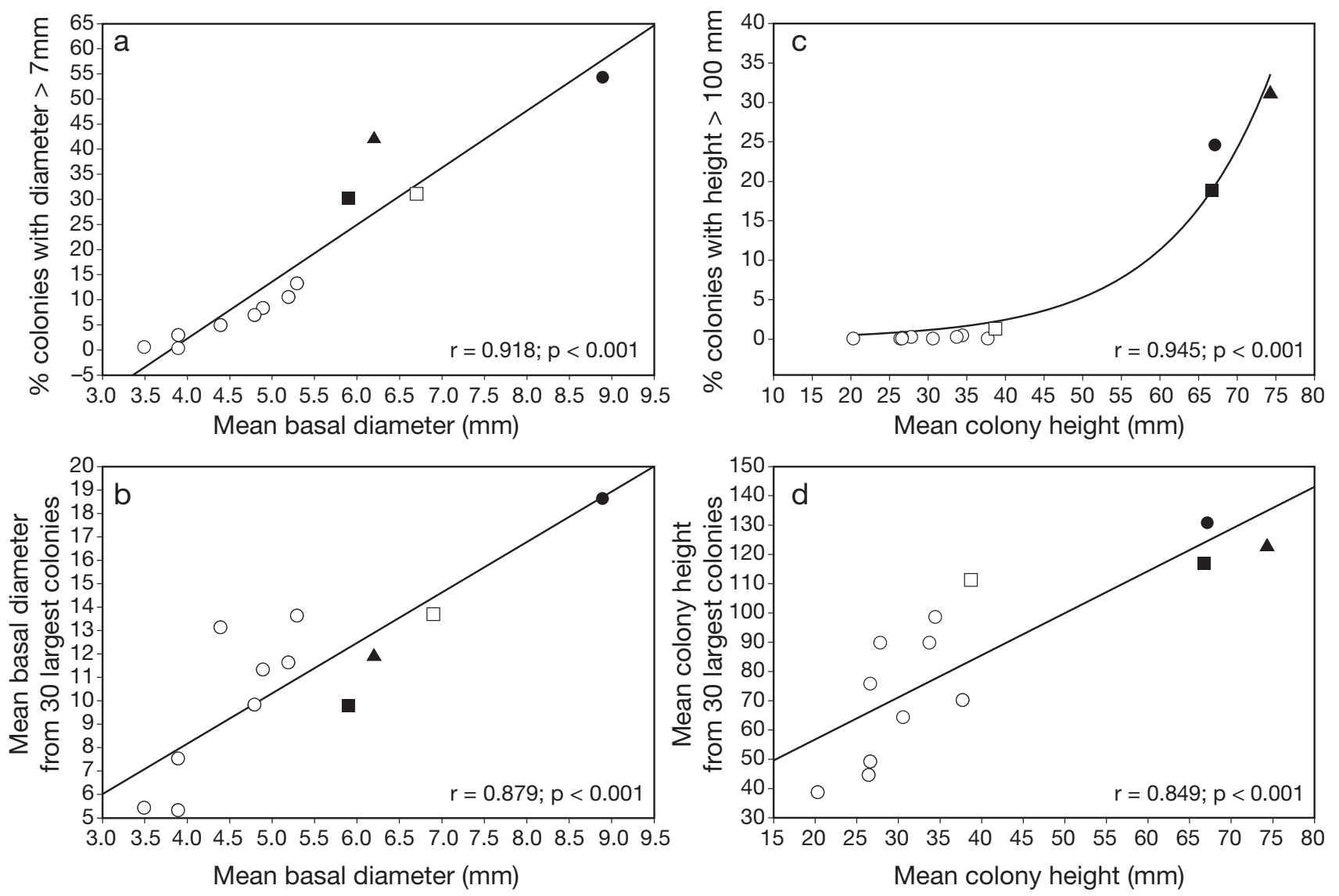

Fig. 4. Corallium rubrum. (a) Relationship between the mean basal diameter and the percentage of colonies displaying basal diameters $>7 \mathrm{~mm}$. (b) Relationship between the mean basal diameter and the mean basal diameter obtained from the 30 largest colonies at each location. (c) Relationship between the mean colony height and the percentage of colonies displaying heights > $100 \mathrm{~mm}$. (d) Relationship between the mean colony height and the mean colony height obtained from the 30 largest colonies at each location. Data were obtained from the 3 studied populations (closed symbols: - Scandola, $\boldsymbol{\Delta}$ Carry-le-Rouet, - Banyuls) and 11 red coral populations (open symbols: $\square$ non-harvested and $\bigcirc$ harvested) compiled from the literature (see Table 2 for reference list) 
density of different populations below $50 \mathrm{~m}$ (about 6 to $9 \mathrm{~mm}$ in diameter, 50 to $60 \mathrm{~mm}$ in height and around 50 colonies $\mathrm{m}^{-2}$, Rossi et al. 2008, Angiolillo et al. 2009) were quite similar to those measured in this study. The similarity of these results emphasises 2 points: (1) the effectiveness of the old MPAs, where harvesting activity is totally forbidden, and (2) the disagreement regarding the clear distinction between shallow populations (up to $50 \mathrm{~m}$ depth, characterised by high density and small colony size) and deep populations (characterised by low density and high colony size) suggested by previous studies (Tsounis et al. 2007, Rossi et al. 2008, Bavestrello et al. 2009). This observation suggests that the lack of a baseline for pristine marine ecosystems (Knowlton \& Jackson 2008) is particularly important for the Mediterranean red coral populations.

The ability of the MPAs to achieve the expected conservation goals depends largely on the population structure present when the MPA was declared. Unfortunately, no surveys of red coral populations were conducted prior to the establishment of the studied reserves in order to facilitate a BACI (before-after control impact) study, as is the case for many older reserves elsewhere (Halpern 2003). In this study, we attempted to overcome the lack of data available on the establishment of the 3 studied MPAs by estimating the former size frequency distribution using growth rates obtained in a previous study (Torrents 2007). It is reasonable to consider that this approximation might lead to an underestimation of the past size distributions because mortality and recruitment rates in the past were not measured. However, bearing in mind that data available for red coral indicate low recruitment rates and low natural mortality rates for decades (less than $1 \%$, Garrabou \& Harmelin 2002, J. G. Harmelin et al. unpubl. data), the range of sizes and the size frequency distributions of large colonies estimated at the beginning of the MPAs can be considered reliable estimations.

As has been demonstrated for fish species, the positive effects of marine reserves are linked to the time elapsed since the establishment of protection (Claudet et al. 2008). However, it is important to note that the differences among the size distributions observed at the 3 MPAs, given the long life span and slow dynamics of this species, are more related to the size distributions in place at the beginning of each MPA (Fig. 3) and, probably, to different recruitment rates than to the number of years of protection. In this sense, the Banyuls population showed starker differences between current and predicted past size distributions than the other 2 studied populations, owing to the probable size distribution at the beginning of the reserve (characterised by a large proportion of the smallest size classes and the low presence of large colonies).
In contrast, in the Carry-le-Rouet and Scandola populations, the differences between the current and predicted past size distributions were less significant, probably due to the presence of colonies within all size classes. However, the protective measures have allowed the conservation of exceptionally large colonies in both MPAs.

In order to assess the conservation goals that can be expected of each MPA, we estimated the future size distribution after another $30 \mathrm{yr}$ of protection. Following the argument outlined above, this method does not provide information on the proportion of small colonies incorporated into the population during these years. However, this approximation forecasts the size of large colonies expected after $30 \mathrm{yr}$ of continued management efforts and may provide reliable information on the potential sizes reached by red coral colonies in populations protected from harvesting. This approach showed that the largest colony size would increase by about $4 \mathrm{~mm}$ in basal diameter in $30 \mathrm{yr}$, highlighting the slow response to protection due to the slow growth rate displayed by this species. Given the longevity of this species (more than 100 yr, Garrabou \& Harmelin 2002, Marschal et al. 2004), it seems reasonable to speculate that $20 \mathrm{yr}$ of protection are not sufficient to reach the size of pristine populations. The sizes of colonies collected in 1962 at Cap de Creus at 25 to $30 \mathrm{~m}$ depth (the largest maximum basal diameter was $45 \mathrm{~mm}$ ) attest that colony size was considerable larger in shallow-water habitats than the observed and expected future values found for these 3 MPAs (Garrabou \& Harmelin 2002).

In spite of the uncertainty inherent in these estimations, the past and future projections for these populations could be valuable for managers of MPAs containing red coral populations, as they delineate the length of time needed to detect positive responses to protection. However, it is important to realise that other environmental and biological factors can have significant effects on the red coral populations. Thus, the size parameters obtained in sites like the Scandola MPA may not be achieved in other protected locations despite the implementation of the most effective management actions.

The comparison of harvested and protected red coral populations using different size parameters also allowed us to identify the most informative descriptors for evaluating conservation status. Since harvesting and poaching principally threaten the largest and most attractive colonies, focusing the analysis on the largest colonies observed in the populations may be a good way to determine the exploitation level (see below). In this sense, clear-cut differences between harvested and non-harvested populations were obtained by measuring the maximum basal diameter and height of the largest colonies in several populations along the 
French coast (Garrabou \& Harmelin 2002). In this study, however, the maximum values of basal diameter and height obtained from all colonies studied did not show striking differences between protected and exploited populations (Table 2).

In contrast, another descriptor based on basal diameter yielded useful results. The proportion of colonies with basal diameters greater than $7 \mathrm{~mm}$ was clearly different between protected and unprotected red coral populations (Fig. 4a). This analysis has thus provided a useful measure to reveal the conservation status of red coral populations and to identify likely legal and/or illegal harvesting activities. In particular, the maximum size values and proportion of large colonies recorded in Scandola MPA are notably high as compared to the shallow red coral populations described to date (Garrabou \& Harmelin 2002, Bianchimani 2005, Tsounis et al. 2006, Santangelo et al. 2007).

The descriptors based on colony height proved to be quite different in the 3 studied MPAs as compared to the other populations, including the Medes Islands MPA. Colony height may be a more useful size parameter for the identification of disturbances causing the breakage of red coral branches and, to a lesser extent, the loss of the entire colonies, such as diving activity, fishing lines or hydrodynamic conditions. It is important to note that while all kinds of human activities except scientific surveys are prohibited in our studied MPAs, diving activity is common in the Medes Islands MPA (Garrabou et al. 1998, Coma et al. 2004).

The percentage of colonies with basal diameters larger than $7 \mathrm{~mm}$ or heights greater than $100 \mathrm{~mm}$ and the mean colony height obtained from the 30 largest colonies are much easier parameters to obtain than the diameter or height of all colonies within the populations. In this sense, these descriptors provide quick and valid static assessments of the conservation status of red coral populations within a large area and could be gradually applied at a Mediterranean-wide scale.

Demographic data for red coral populations from areas where all human activities are prohibited, in combination with previous studies focused on the size structure of shallow and deep red coral populations (Tsounis et al. 2006, Santangelo et al. 2007, Rossi et al. 2008), contribute to a better understanding of the current status of red coral in the NW Mediterranean Sea. This study may be useful to managers because it provides evidence in support of the fundamental objectives of marine reserves as well as validated descriptors to assess the conservation status of red coral populations.

Acknowledgements. The authors gratefully acknowledge the field assistance of the staff of the Réserve Naturelle de Scandola (Parc Regional de Corse), Réserve Marine de Carry-leRouet (Parc Marin de la Cote Bleu) and Réserve Naturelle Marine de Cérbere-Banyuls. We also thank R. Graille and F.
Zuberer (Centre d'Océanologie de Marseille) for their assistance during sampling. Dr. G. Tsounis kindly provided data on red coral populations from the Spanish coasts. C.L. was funded by a postdoctoral fellowship from the 'Ministerio de Ciencia e Innovación' of Spain. This study was funded by the Agence Nationale de la Recherche (Medchange project).

\section{LITERATURE CITED}

Angiolillo M, Canese S, Salvati Giousti M, Cardinali A, Bo M, Greco S (2009) Presence of Corallium rubrum on coralligenous assemblages below $50 \mathrm{~m}$ along Calabrian Coast (South Italy). Proc 1st Medit Symp Conservation of the Coralligenous and Other Calcareous Bio-concretions, Tabarka, Tunis, p 46-51

Bavestrello G, Cerrano C, Cattaneo-Vietti R (2009) Biological interactions affecting the growth rates of red coral (Corallium rubrum) colonies. Proce 1st Medit Symp Conservation of the Coralligenous and Other Calcareous Bio-concretions, Tabarka, Tunis, p 52-57

Bianchimani O (2005) Évaluation des effets des aires marines protégées sur les populations de corail rouge (Corallium rubrum): le cas des réserves marines françaises. DU d'Environment et Pollution, Université de la Méditerranée, Marseille

Bramanti L (2003) Dinamica di populazione ed adattamenti demografici di una popolazione costiera di corallo rosso (Corallium rubrum, L. 1758) con particolare riferimento al reclutamento. $\mathrm{PhD}$ thesis, Univesitá degli studi di Pisa

Bramanti L, Rossi S, Tsounis G, Gili JM, Santangelo G (2007) Recruitment and early survival of red coral on settlement plates: some clues for demography and restoration. Hydrobiologia 580:219-224

Claudet J, Osenberg CW, Benedetti-Cecchi L, Domenici P and others (2008) Marine reserves: size and age do matter. Ecol Lett 11:481-489

Coma R, Pola E, Ribes M, Zabala M (2004) Long-term assessment of the patterns of mortality of a temperate octocoral in protected and unprotected areas: a contribution to conservation and management needs. Ecol Appl 14:1466-1478

Dayton PK, Thrush SF, Tundi Agardy M, Hofman RJ (1995) Environmental effects of marine fishing. Aquat Conserv: Mar Freshw Ecosyst 5:205-232

Drap P (1997) Photogrammétrie et modèles architecturaux. PhD Thesis. Université d'Aix-Marseille III

> Forbis TA, Doak DF (2004) Seedling establishment and life history trade-offs in alpine plants. Am J Bot 91:1147-1153

Franco M, Silvertown J (2004) A comparative demography of plants based upon elasticities of vital rates. Ecology 85: 531-538

Francour F, Harmelin JG, Pollard D, Sartoretto S (2001) A review of marine protected areas in the northwestern Mediterranean region: siting, usage, zonation and management. Aquat Conserv: Mar Freshw Ecosyst 11:155-188

Garrabou J, Harmelin JG (2002) A 20-year study on life-history traits of a harvested long-lived temperate coral in the NW Mediterranean: insights into conservation and management needs. J Anim Ecol 71:966-978

Garrabou J, Sala E, Arcas A, Zabala M (1998) The impact of diving on rocky sublittoral communities: a case study of a bryozoan population. Conserv Biol 12:302-312

> Garrabou J, Perez T, Sartoretto S, Harmelin JG (2001) Mass mortality event in red coral Corallium rubrum populations in the Provence region (France, NW Mediterranean). Mar Ecol Prog Ser 217:263-272

Garrabou J, Coma R, Benssoussan N, Chevaldonné P and oth- 
ers (2009) Mass mortality in NW Mediterranean rocky benthic communities: effects of the 2003 heat wave. Glob Change Biol 15:1090-1103

Grigg RW (1989) Precious coral fisheries of the Pacific and Mediterranean. In: Caddy FJ (ed) Marine invertebrate fisheries: their assessment and management. John Wiley and Sons, New York, p 637-645

Grigg RW (1993) Precious coral fisheries of Hawaii and U.S Islands. Mar Fish Rev 55:50-60

Halpern B (2003) The impact of marine reserves: do reserves work and does reserve size matter? Ecol Appl 13:117-137

- Halpern B, Warner RR (2002) Marine reserves have rapid and lasting effects. Ecol Lett 5:361-366

Harley CDG, Hughes AR, Hultgren KM, Miner BG and others (2006) The impacts of climate change in coastal marine systems. Ecol Lett 9:228-241

Harvell CD, Kim K, Burkholder JM, Colwell RR and others (1999) Emerging marine diseases-climate links and anthropogenic factors. Science 285:1505-1510

Hastings A, Botsford LW (2003) Comparing designs of marine reserves for fisheries and for biodiversity. Ecol Appl 13: 65-70

Jackson JBC (2001) What was natural in the coastal oceans? Proc Natl Acad Sci USA 98:5411-5418

> Jennings S, Kaiser MJ (1998) The effects of fishing on marine ecosystems. Adv Mar Biol 34:201-352

Knowlton N, Jackson JBC (2008) Shifting baselines, local impacts, and global change on coral reefs. PLoS Biol 6:e54

Linares C, Diaz D, Hereu B, Zabala M (2003) Avaluació de la població de corall vermell Corallium rubrum de les Illes Medes. Technical Report. Departament de Medi Ambient, Generalitat de Catalunya, Barcelona

Linares C, Doak DF, Coma R, Diaz D, Zabala M (2007) Life history and population viability of a long-lived marine invertebrate: the octocoral Paramuricea clavata. Ecology 88:918-928

Linares C, Coma R, Garrabou J, Diaz D, Zabala M (2008) Size distribution, density and disturbance of two Mediterranean gorgonians: Paramuricea clavata and Eunicella singularis. J Appl Ecol 45:688-699

Marschal C, Garrabou J, Harmelin JG (2004) A new method for measuring growth and age in the precious red coral Corallium rubrum (L.). Coral Reefs 23:423-432

McCarty JP (2001) Ecological consequences of recent climate change. Conserv Biol 4:52-62

McClanahan TR, Ateweberhan M, Omukoto J (2008) Longterm changes in coral colony size distributions on Kenyan reefs under different management regimes and across the

Editorial responsibility: Charles Birkeland, Honolulu, Hawaii, USA
1998 bleaching event. Mar Biol 153:755-768

Meesters EH, Hilterman M, Kardinaal E, Keetman M, de Vries M, Bak RPM (2001) Colony size-frequency distributions of scleractinian coral populations: spatial and interspecific variation. Mar Ecol Prog Ser 209:43-54

Parnell PE, Lennert-Cody CE, Geelen L, Stanley LD, Dayton PK (2005) Effectiveness of a small marine reserve in southern California. Mar Ecol Prog Ser 296:39-52

Roark EB, Guilderson TP, Dunbar RB, Ingram BL (2006) Radiocarbon-based ages and growth rates of Hawaiian deep-sea corals. Mar Ecol Prog Ser 327:1-14

Rossi S, Tsounis G, Orejas C, Padrón T and others (2008) Survey of deep-dwelling red coral (Corallium rubrum) populations at Cap de Creus (NW Mediterranean). Mar Biol 154:533-545

$>$ Russ GR, Alcala AC (1998) Natural fishing experiments in marine reserves 1983-93: roles of life history and fishing intensity in family responses. Coral Reefs 17:399-416

Santangelo G, Abbiati M, Giannini G, Cicogna F (1993a) Red coral fishing trends in the western Mediterranean Sea. Sci Mar 57:139-143

Santangelo G, Abbiati M, Caforio G (1993b) Age structure and population dynamics in Corallium rubrum. In: Cicogna F, Cattaneo-Vietti R (eds) Red coral in the Mediterranean Sea: art, history and science. Ministerio delle Risorse Agricole, Almentari e Forestali, Roma, p 131-157

Santangelo G, Bramanti L, Iannelli M (2007) Population dynamics and conservation biology of the over-exploited Mediterranean red coral. J Theor Biol 244:416-423

Sokal R, Rohlf FJ (1995) Biometry. The principles and practice of statistics in biological research, 3rd edn. Freeman, New York

Torrents O (2007) Biologie des populations du corail rouge de Méditerranée. PhD Thesis, Université de la Méditerranée, Marseille

Torrents O, Garrabou J, Marshal C, Harmelin JG (2005) Age and size at first reproduction in the commercially exploited red coral Corallium rubrum (L.) in the Marseilles area (France, NW Mediterranean). Biol Conserv 121: 391-397

> Tsounis G, Rossi S, Gili JM, Arntz W (2006) Population structure of an exploited benthic cnidarian: the case study of red coral (Corallium rubrum L.). Mar Biol 149:1059-1070

> Tsounis G, Rossi S, Gili JM, Arntz W (2007) Red coral fishery at the Costa Brava (NW Mediterranean): case study of an overharvested precious coral. Ecosystems 10:975-986

Vitousek PM, Mooney HA, Lubchenco J, Melillo JM (1997) Human domination of Earth's ecosystems. Science 277: 494-499

Submitted: August 3, 2009; Accepted: November 24, 2009 Proofs received from author(s): February 21, 2010 